\title{
HUBUNGAN PENGETAHUAN IBU DENGAN KEJADIAN PNEUMONIA PADA BALITA DI PUSKESMAS KEBUN HANDIL KOTA JAMBI
}

\author{
Salvita Fitrianti \\ Program Studi Ilmu Keperawatan \\ Sekolah Tinggi Ilmu Kesehatan Baiturrahim Jambi \\ Salvita.fitrianti@gmail.com
}

\begin{abstract}
Pneumonia is one of the biggest health problems and the leading cause of death of children under five years old (infants). The public health center Kebun Handil is the public health center with the highest number of pneumonia infants in Jambi city as many as 222 toddlers in 2016. This study aimed at determining the correlation of mother's knowledge and the characteristics of the house with the incidence of pneumonia in infants at the public health center Kebun Handil Jambi city. This is a quantitative research, using Cross Sectional design, and the population of this research is all of infants at the public health center Kebun Handil year 2016 as many as 3.731. The sample was using Accidental Sampling technique, as many as 94 people. This research used Chi Square test. The research was conducted at the public health center Kebun Handil. The findings indicated that almost respondents (56.4\%) have low knowledge, and (53.2\%) infants respondents with pneumonia. The result of analysis bivariateChi-Square indicated that there is the correlation between mother's knowledge with pneumonia in infants ( $p$ value $=0.003<$ alpha 0.05). It is necessary to increase the extension to the public about pneumonia toddlers in order to improve the knowledge of the respondents. The counseling results are expected to increase public knowledge of pneumonia and its prevention.
\end{abstract}

Keywords: Incidence of Pneumonia;Knowledge

\begin{abstract}
Pneumonia merupakan salah satu masalah kesehatan dan penyumbang terbesar penyebab kematian anak usia dibawah lima tahun (balita). Puskesmas Kebun Handilmerupakan puskesmas dengan jumlah penderita pneumonia balita tertinggi di kota Jambi sebanyak 222 balita di tahun 2016. Penelitian ini merupakan penelitian kuantitatif, dengan desain cross sectional yang bertujuan untuk mengetahui hubungan pengetahuan ibu dan karakteristik rumah dengan kejadian pneumonia pada balita di wilayah kerja Puskesmas Kebun handil tahun 2016 yang berjumlah 3.731. Sampel pada penelitian ini dipilih dengan teknik accidental samplin, yang berjumlah 94 orang. Penelitian ini dianalisa dengan menggunakan uji statistik chi square, di puskesmas kebun handil. Hasil penelitian memperlihatkan sebagian responden $(44,7 \%)$ memiliki pengetahuan rendah, responden yang menderita pneumonia sebesar 53,2\%. Hasil analisis Chi-Square menunjukkan ada hubungan antara pengetahuan ibu dengan kejadian pneumonia pada balita $(p$-value $=0,003<$ alpha 0,05$)$. Untuk meningkatkan pengetahuan responden, maka perlu ditingkatkan penyuluhan kepada masyarakat tentang pneumonia balita. Hasil penyuluhan tersebut diharapkan dapat meningkatkan pengetahuan masyarakat terhadap pneumonia dan pencegahannya.
\end{abstract}

Kata kunci : Pengetahuan; Kejadian Pneumonia 


\section{PENDAHULUAN}

Pneumonia merupakan salah
satu masalah kesehatan dan
penyumbang terbesar penyebab
kematian anak usia di bawah lima
tahun (anak-balita). Pneumonia
membunuh anak lebih banyak
daripada penyakit lain apapun,
mencakup hampir 1 dari 5 kematian
anak-balita, membunuh lebih dari 2
juta anak-balita setiap tahun yang
sebagian besar terjadi di negara
berkembang. Oleh karena itu
pneumonia disebut sebagai
pembunuh anak nomor 1 (the
number one killer of children). Di
negara berkembang pneumonia
merupakan "penyakit yang
terabaikan" (the neglegted disease)
atau "penyakit yang terlupakan" (the
forgotten disease) karena begitu
banyak anak yang meninggal karena
pneumonia namun sangat sedikit
perhatian yang diberikan kepada
masalah pneumonia. ${ }^{2}$ Faktor-faktor yang berpengaruh terhadap kejadian pneumonia pada balita adalah jenis kelamin, tipe tempat tinggal, pendidikan ibu, tingkat ekonomi/kuantil indeks kepemilikan,letak dapur, keberadaan/kebiasaan membuka jendela dan ventilasi kamar tidur. ${ }^{3}$

Menurut Laporan Program Pengendalian ISPA Dinas Kesehatan Kota Jambi tahun 2015 - 2016, penduduk usia balita tahun 2015 berjumlah 601.015 jiwa dan tahun 2016 berjumlah 74,642 jiwa. Puskesmas Kebon Handil merupakan satu dari 20 puskesmas dengan jumlah penderita pneumonia sebanyak 222 kasus $(5,95 \%){ }^{4}$

Tujuan penelitian adalah mengetahuigambaran pengetahuan ibu, dan kejadian pneumonia serta untuk mengetahui Hubungan Pengetahuan Ibu Kejadian Pneumonia pada Balita di Puskemas Kebun Handil Kota Jambi.

\section{METODE PENELITIAN}

Jenis penelitian ini adalah penelitian kuantitatif dengan metode cross sectional ${ }^{5}$. Populasi pada penelitian ini adalah seluruh balita di Puskesmas Kebun Handil Kota Jambi berjumlah 3.731 balita pada tahun 2016. Sampel pada penelitian ini berjumlah 94 responden, pengambilan sampel dilakukan dengan teknik accidental sampling dengan kriteria inklusi : Ibu yang memiliki anak usia balita (12 - 59 bulan) dan datang ke puskesmas, bersedia menjadi responden dan dalam kondisi sehat, bisa berkomunikasi dengan baik.

Pengukuran pengetahuan ibu menggunakan kuesioner yang berisi 15 pertanyaan. Analisa data dilakukan secara univariat dan bivariat menggunakan uji Chi square.

\section{HASIL DAN PEMBAHASAN}

\section{Karakteristik Responden}

Tabel 1. Distribusi responden menurut karakteristik responden

\begin{tabular}{lcl}
\hline Umur & $\mathrm{N}$ & $(\%)$ \\
\hline$\leq 25$ & 32 & 34.04 \\
$26-35$ & 47 & 50 \\
$36-45$ & 15 & 15.96 \\
Pendidikan & & \\
SD & 14 & 14.9 \\
SMP & 44 & 46.8 \\
SMA & 32 & 34,0 \\
Perguruan Tinggi & 4 & 4,3 \\
Pekerjaan & &
\end{tabular}




\begin{tabular}{lcc} 
PNS & 2 & 2.13 \\
Honor & 2 & 2.13 \\
Karyawan swasta & 32 & 34.04 \\
IRT $\quad 58$ & 61.7 \\
$\quad$ Usia balita & & \\
12 - 24 bulan & 31 & 32,98 \\
25 - 36 bulan & 26 & 27,66 \\
$37-48$ bulan & 13 & 13,83 \\
$49-59$ bulan & 24 & 25,53 \\
\hline
\end{tabular}

Tabel 1 menunjukan banyak responden yang berumur antara 2635 tahun (50\%), berpendidikan SMP yaitu 46,8\%, ibu rumah tangga $61,7 \%$, dan usia balita antara 12-24 bulan $(32,98 \%)$.

\section{Analisa univariat}

\section{Kejadian Pneumonia}

Tabel 2. Distribusi Responden berdasarkan kejadian Pneumonia

\begin{tabular}{clcc}
\hline No & $\begin{array}{c}\text { Kejadian } \\
\text { Pneumonia }\end{array}$ & Jmlh & $\%$ \\
\hline 1 & Pneumonia & 50 & 53.2 \\
2 & Bukan & 44 & 46,8 \\
pneumonia & 44 & 100 \\
\hline
\end{tabular}

Hasil penelitian tabel 2 terhadap 94 balita, gambaran kejadian Pneumonia di Wilayah Puskesmas Kebun Handil Kota Jambi Tahun 2017, sebanyak 50 balita $(53,2 \%)$ memiliki masalah kejadian Pneumonia dan sebanyak 44 balita $(46,8 \%)$ bukan Pneumonia.

\section{Pengetahuan}

Tabel 3. Distribusi responden berdasarkan tingkat pengetahuan

\begin{tabular}{llcc}
\hline No & Pengetahuan & Jumlah & \% \\
\hline 1 & Rendah & 42 & 44,7 \\
2 & Tinggi & 52 & 55,3 \\
& Jumlah & 94 & 100 \\
\hline \multicolumn{4}{c}{ Berdasarkan tabel 3 di atas } \\
dapat diketahui bahwa dari 94 \\
responden, diketahui bahwa $(44,7 \%)$ \\
memiliki pengetahuan rendah.
\end{tabular}

Analisa Bivariat

Tabel 4. Hasil analisis hubungan antara pengetahuan ibu dengan kejadian Pneumonia dapat dilihat pada tabel berikut ini :

\begin{tabular}{|c|c|c|c|c|c|c|c|c|}
\hline \multirow[b]{2}{*}{ No } & \multirow[b]{2}{*}{$\begin{array}{l}\text { Pengetahua } \\
\text { n }\end{array}$} & \multicolumn{4}{|c|}{ Kejadian Pneumonia } & \multicolumn{2}{|l|}{ Total } & \multirow[t]{2}{*}{$\begin{array}{l}P \text { - } \\
\text { Value }\end{array}$} \\
\hline & & $\begin{array}{l}\text { Pneumoni } \\
\text { a }\end{array}$ & $\%$ & $\begin{array}{l}\text { Tidak } \\
\text { Pneumoni } \\
\text { a }\end{array}$ & $\%$ & $\begin{array}{l}\text { Tota } \\
\text { l }\end{array}$ & $\%$ & \\
\hline 1 & Rendah & 30 & 71,4 & 12 & 28,6 & 42 & $\begin{array}{l}100, \\
0\end{array}$ & 0,003 \\
\hline 2 & Tinggi & 20 & 38,5 & 32 & 61,5 & 52 & $\begin{array}{l}100 \\
0\end{array}$ & \\
\hline Tota & & 50 & 53,2 & 44 & 46,8 & 94 & $\begin{array}{l}100 \\
0\end{array}$ & \\
\hline
\end{tabular}


Berdasarkan Tabel 4 di atas dapat dilihat bahwa dari 94 responden, sebanyak 42 responden berpengetahuan rendah, $71,4 \%$ balitanya mengalami Pneumonia. Hasil uji statistik diperoleh nilai $p$ value $=0,003(\mathrm{p}<0,05)$. Hal ini menunjukan ada hubungan yang bermakna antara pengetahuan dengan kejadian Pneumonia. Pada tabel di atas juga terlihat masih terdapat $38,5 \%$ ibu dengan pengetahuan tinggi tapi balitanya mengalami pneumonia. Hal ini menunjukkan bahwa kejadian pneumonia pada balita bukan hanya disebabkan oleh rendahnya pengetahuan ibu tapi juga disebabkan oleh faktor-faktor yang lain, yaitu faktor yang mempengaruhi kejadian pneumonia pada balita adalah jenis kelamin,tipe tinggal,pendidikanibu,tingkat ekonomi/kuantil indeks kepemilikan, letak dapur, keberadaan/kebiasaan membuka jendela dan ventilasi kamar tidur. $^{6}$

Hasil penelitian ini sesuai dengan hasil penelitian sebelumnya yang telah dilakukan oleh Azizah, dengan judul penelitian tingkat pengetahuan dan pendidikan ibu balita dengan kejadian Pneumonia di kelurahan Keraton Kecamatan Martapura Kabupaten Banjar, jumlah responden sebanyak 94. Hasil analisis bivariat diperoleh hasil pvalue $(0,000)<$ alpha $(0,05)$, ada hubungan yang bermakna antara tingkat pengetahuan ibu dengan kejadian Pneumonia pada balita, serta diperoleh koefisien kontingensi $(\mathrm{R}=0,44)^{7}$ yang artinya ada hubungan yang kuat antara tingkat pengetahuan ibu dengan kejadian penyakit Pneumonia. Sedangkan arah korelasi bernilai positif maka ada hubungan searah antara 2 variabel.

Berdasarkan hasil penelitian menunjukan bahwa sebagian besar responden memiliki pengetahuan yang tinggi tentang penyakit Pneumonia, namun sebagian lagi masih memiliki pengetahuan yang rendah tentang penyakit pneumonia. Penyebab dari rendahnya pengetahuan dapat disebabkan karena masih tingginya ketidaktahuan responden terhadap akibat lanjut yang diakibatkan oleh Pneumonia pada balita jika tidak segera di tanggulangi.

Hal ini sesuai dengan teori, bahwa tingkat pengetahuan ibu sangat berperan besar terhadap kejadian Pneumonia pada balita. Hal ini berkaitan dengan perilaku ibu dalam memberikan makanan yang memadai dan bergizi kepada anaknya serta perilaku ibu dalam pertolongan, perawatan, pengobatan, serta pencegahan Pneumonia. ${ }^{8}$

Menurut penelitian yang dilakukan oleh Rahim menyatakan pengetahuan yang baik pada ibu tentang pencegahan Pneumonia pada anak dapat membuat perilaku ibu menjadi lebih baik pula dalam melakukan pencegahan atau perawatan pada anak. ${ }^{9}$ Menurut peneliti semakin tinggi pengetahuan danpendidikanibu semakin baik kemampuan ibu dalam menerima informasi yang terkait dengan penyakit pneumonia. Sedangkan ibu yang tidak memiliki pengetahuan yang cukup tentang Pneumonia, akan menganggap remeh dan bahkan tidak 
mendukung upaya pencegahan penyakit pneumonia, hal ini berdampak terhadap tingginya angka kesakitan dan kematian Pneumonia pada balita. Sehingga responden dengan pengetahuan tinggi, maka pemahamannya akan lebih baik tentang Pneumonia dibandingkan dengan responden yang memiliki pengetahuan rendah.

Ditinjau dari latar belakang pendidikan, ibu balita di Puskesmas Kebun Handil yang tamat SD sebanyak (14,9\%) dan SMP sebanyak (46,8\%). Sebagian besar pendidikan responden masih dalam kategori pendidikan rendah. Latar belakang pendidikan erat kaitannya dengan pengetahuan yang dimilikinya. Pengetahuan tersebut diperoleh antara lain melalui pendidikan. Pendidikan itu sendiri adalah dasar terbentuknya perilaku seseorang sehingga pendidikan dikatakan sebagai faktor kedua terbesar dari faktor sosial ekonomi yang mempengaruhi status kesehatan. Seseorang yang memiliki tingkat pendidikan yang tinggi akan memiliki pengetahuan dan sikap yang baik tentang kesehatan sehingga akan mempengaruhi perilakunya untuk hidup sehat. Pendidikan yang cukup pada seseorang akan memudahkan untuk mencari dan menerima informasi dari luar, khususnya yang berkaitan dengan penyakit Pneumonia sehingga responden bisa segera melakukan tindakan pencegahan.

Hal ini beralasan karena tingkat pengetahuan yang baik tentang penyakit Pneumonia berefek kepada responden yang akan memiliki kemampuan atau pengetahuan untuk melakukan antisipasi dan pencegahan terhadap kejadian Pneumonia pada balita, sehingga dapat mengurangi jumlah frekuensi terjadinya Pneumonia pada balita itu sendiri.

Langkah pertama dalam mengatasi kurangnya pengetahuan ibu tentang penyakit Pneumonia adalah dengan memberikan penyuluhan. Hal ini perlu upaya tenaga kesehatan untuk memberikan informasi dan keterampilan baik melalui penyuluhan kesehatan yang dapat di optimalkan dengan menggerakan kader-kader yang berada di tengah masyarakat untuk menyampaikan pendidikan kesehatan dan juga memantau perubahan perilaku dari masyarakat setalah diberikan pendidikan kesehatan. Upaya lainnya dapat langsung dilakukan oleh petugas kesehatan yaitu pada saat kegiatan konseling ketika ibu melakukan pemeriksaan balitanya ke Puskesmas sehingga meningkatkan pengetahuan dan wawasan ibu dalam melakukan pencegahan sedini mungkin untuk menghindarkan balitanya dari faktorfaktor penyebab kejadian penyakit ISPA Khususnya Pneumonia maupun upaya peningkatan kesehatan serta pemberian zat kekebalan tubuh melalui pemberian imunisasi lengkap.

\section{SIMPULAN}

1. Hasil penelitian terdapat $(44,7 \%)$ responden yang pengetahuan rendah tentang Pneumonia pada balita.

2. Hasil penelitian terdapat $(53,2 \%)$ responden mengalami Pneumonia pada balitanya 
3. Ada hubungan pengetahuan ibu dengan kejadian Pneumonia pada balita di Puskesmas Kebun Handil Kota Jambi dimana $p$ value $0,003<$ alpha 0,05

\section{SARAN}

1. Bagi Dinas Kesehatan Kota Jambi. Berdasarkan hasil penelitian yang telah dilakukan, peneliti berharap kepada Dinas Kesehatan Kota Jambi untuk melakukan perencanaan penanggulangan dan evaluasi terhadap program penanggulangan penyakit menular, khususnya penyakit Pneumonia.

2. Bagi Puskesmas Kebun Handil. Berdasarkan hasil penelitian yang telah dilakukan, peneliti berharap kepada Puskesmas Kebun Handil agar lebih meningkatkan pengembangan dan evaluasi terhadap program MTBS khususnya yang berkaitan dengan Pneumonia agar dapat memberikan penyuluhan tentang bahaya pneumonia pada masyarakat.

3. Bagi Peneliti Selanjutnya.Diharapkan dapat melakukan penelitian dengan variabel lain seperti status gizi dan status imunisasi pada balita.

\section{DAFTAR PUSTAKA}

1. Widoyono. Epidemiologi,
Penularan, Pencegahan dan

Pemberantasn Penyakit

Tropis. Jakarta: Erlangga; 2008.

2. kemenkes RI. Buletin

Pneumonia Indonesia. 2010. www.depkes.go.id.

3. Athena dkk. Pneumonia Pada Anak Balita,. Jakarta: Kemenkes RI; 2013.

4. dinkes kota jambi. Data kejadian pneumonia.(2016).

5. Hamid A. Buku Ajar Riset Keperawatan. 2 ed. Jakarta: EGC; 2015.

6. Mahmud R. Pneumonia Balita di Indonesia. Padang: Andalas University Press; 2008.

7. Azizah dkk. Tingkat pengetahuan dan pendidikan ibu balita dengan kejadian penyakit Pneumonia pada balita di Kelurahan Keraton Kecamatan Martapura Kabupaten Anjar. 2012.

8. Yuwono D. Hubungan Tingkat Pengetahuan Ibu dan Lama Pemberian ASI pada Balita Terhadap Kejadian Pneumonia di Wilayah Kerja Puskesmas. 2007.

9. Rahim R. Hubungan Pengetahuan ibu dan sikap ibu dengan perilaku pencegahan penyakit pneumonia di wilayah kerja puskesmas Putri Ayu. 2013. 